\title{
The relationship between dento-maxilary anomalies and postural diseases
}

\author{
Relaţia dintre anomaliile dento-maxilare şi disfuncţiile posturale
}

\author{
Liviu Gavrilă-Ardelean', Horia Lăzărescu², Andrei Kozma³, Agnes K. Lackner, \\ Cristian Teodorescu ${ }^{5}$, Monica loana Teodorescu, ${ }^{3,5}$ \\ ${ }^{1}$ Universitatea de Vest „Vasile Goldiş“, Arad, România \\ ${ }^{2}$ Institutul Naţional pentru Recuperare, Medicină fizică şi Balneoclimatologie, Bucureşti, România \\ ${ }^{3}$ Institutul National pentru Sănătatea Mamei şi a Copilului „Alessandrescu-Rusescu“, \\ Bucureşti, România \\ ${ }^{4}$ Departamentul de Stomatologie Pediatrică, Clinica Dentară, Universitatea Medicală, Vienna, Austria \\ 5Universitatea de Medicină şi Farmacie „Carol Davila“, Bucureşti, România
}

\begin{abstract}
The aim of the study is to address integratively the ora and maxillofacial pathology of various etiology, so that starting from the dental anomaly we could prevent somatic imbalances, by rebalancing the postural tonic system (STP). The present research shows that this wish can only be achieved in a multidisciplinary therapeutic team, composed of the dentist, the specialist in medical recovery and the doctor of the primary healthcare facility. The etiological treatment is practically the one that prevents somatic changes in the spine and not the symptomatic therapy. The etiological treatment per se is a method of secondary and tertiary prophylaxis of axial somatic disorders.
\end{abstract}

Keywords: dento-maxillary abnormalities, postural dysfunctions, integrative medicine, multidisciplinary team, causalities, etiological therapy

\begin{abstract}
REZUMAT
Scopul studiului este de a aborda integrativ patologia buco-maxilo-dentară de etiologie variată, astfel încât, plecând de la anomalia dentară, să prevenim dezechilibrele somatice, prin reechilibrarea sistemului tonic postural (STP). Cercetarea de faţă arată că acest deziderat nu poate fi realizat decât într-o echipă terapeutică pluridisciplinară, compusă din medicul dentist, medicul specialist în recuperare medicală şi medicul din asistenţa medicală primară. Tratamentul etiologic este, practic, cel care previne modificările somatice de la nivelul coloanei vertebrale şi nu terapia simptomatică. Tratamentul etiologic per se este o metodă de profilaxie secundară şi terţiară a tulburărilor somatice axiale.
\end{abstract}

Cuvinte cheie: anomalii dento-maxilare, disfuncţii posturale, medicină integrativă, echipă multidisciplinară, cauzalităţi, terapie etiologică

\section{INTRODUCERE}

Medicina bazată pe dovezi a secolului al XXIlea are la bază experimentele ştiinţifice care vin să valideze observaţiile istorice ale fenomenelor medicale fiziologice. Izvoarele istorice povestesc despre faptul că, în Antichitate, vâslaşii din închisorile de pe nave muşcau o bucată de lemn la creşterea ritmului de vâslire. Alte observaţii de cauzalitate a efectelor somatice ale efortului fizic asupra aparatului buco-maxilo-dentar au arătat că este cu atât mai dificilă realizarea unui efort cu gura deschisă şi limba în protruzie cu cât efortul fizic este mai mare şi respiraţia mai intensă. Aceste mici reacţii de tip cauză-efect ne ajută să observăm cum stimularea peste prag a receptorilor bucali generează modificări specifice la nivelul întregului organism. Studiile sistemul stomatognatic realizate de cercetători din domeniul medical au arătat legături între variaţiile de postură şi aparatul buco-maxilo-dentar.

Echilibrul extremităţii cefalice este influenţat de elementele aparatului dento-maxilar şi relaţia aces- 
tuia cu restul scheletului. Forţa de gravitaţie şi acţiunea musculaturii sunt factori ce influenţează menţinerea organsimului în poziţia bipedă a omului, fiind o consecinţă a modificărilor coloanei vertebrale şi neurocraniului.

Coloana vertebrală este comparată cu o spirală cu pasul foarte mare, un stâlp elastic cu 4 curburi în plan sagital, 2 curburi cu concavitatea posterioară cervicală şi lombară şi 2 cu concavitatea anterioară toracală şi sacrată. Impactul alinierii planului sagital asupra tratamentului afecţiunilor coloanei vertebrale este considerat a fi de o importanţă critică (1). Centrul de greutate al capului este situat cu 0,5-1 cm mai anterior faţă de articulaţia atlanto-occipitală, tendinţa acestuia fiind de a cădea spre înainte, musculatura cefei alături de muşchii aparatului dento-maxilar şi ai gâtului asigurând poziţia sa statică şi dinamică. La acest echilibru participă muşchii mobilizatori ai mandibulei.

Mişcările fundamentale ale mandibulei funcţionale nu vor perturba poziţia capului datorită reflexelor proprioceptive. Modificările de poziţie ale capului au fost remarcate în timpul exercitării funcţiilor aparatului dento-maxilar la pacienţi cu afectare neuro-musculară (2).

Conform cu definiţia sănătăţii, dată de Organizaţia Mondială a Sănătăţii, ca stare completă de bine şi nu doar absenţa bolii sau a infirmităţii (3), dezideratul abordării integrative a stării de bine a individului este aplicat în cercetarea de faţă.

\section{IMPORTANȚA PROBLEMATICII}

În Europa, 47,6\% din populaţie suferă de dureri ale coloanei vertebrale, pierzând 26.000 .000 de zile de muncă, în unele circumstanţe în care durerile puteau fi tratate printr-o colaborare dintre medicii specialişti care să caute etiologia problemelor şi în cavitatea bucală a pacientului. S-a înregistrat o incidenţă în creştere a problemelor patologice ale aparatul stomatognat şi a anomaliilor de postură la pacienţii tineri.

Literatura de specialitate menţionează că la originea anomaliilor aparatului dento-maxilar participă, alături de interpoziţiile heterotrope, autotrope sau alte obiceiuri vicioase generatoare de forțe nocive în timpul desfăşurării improprii a unor funcţii, şi postura capului şi a corpului atât în somn, cât şi în starea de veghe.
Hiperflexia extremităţii cefalice faţă de corp în timpul somnului poate favoriza deplasarea spre înainte a mandibulei, situaţie întâlnită în relaţiile prognate, pe când hiperextensia capului favorizează poziţionarea spre posterior a mandibulei, situaţie caracteristică relaţiilor retrognate.

Conform aceluiaşi principiu, obiceiul de a dormi într-un singur decubitus lateral poate influenţa dezvoltarea ulterioară a unei asimetrii faciale şi a unei devieri laterale a mandibulei. Persistenţa acestor posturi anormale din timpul copilăriei până la vârsta adultă poate avea efect nociv asupra dezvoltării aparatului dento-maxilar în aceeaşi manieră precum o pot face atitudinile de postură incorecte în starea de veghe (2). Scopul acestei lucrări este orientat spre demonstrarea cauzalităţilor şi a utilităţii metodelor terapeutice integrate, multidisciplinare, pentru ca efectele planului de tratament şi recuperarea a acestei categorii de populaţie activă să fie cât mai complete şi eficiente pentru pacienţi.

Receptorii tactili, termici şi de presiune de la nivelul mucoasei bucale, a limbii, a dinţilor şi ai parodonţiului dentar recepţionează stimulii externi şi interni, de unde sunt conduşi la nivelul sistemului nervos central. Stimulii cu intensitatea peste prag excită nucleul motor masticator, care trimite comanda de contracţie muşchilor masticatori, care mobilizează mandibula (4).

Limba, componentă a sistemului stomatognat, influenţează echilibrul muscular, prin originea comună pe osul hiod cu muşchii supra- şi infrahioidieni. În cazul unui pacient edentat, lipsa dinţilor şi poziţia patologică a maxilarelor edentate determină o poziţie deficitară a umerilor şi a capului, determinând astfel disfuncţii posturale, măsurabile cu ajutorul scoliometrului şi a podometrului $(5,6,7,8)$. Toate aceste modificări sunt un factor de dezechilibru atât al unităţii masticatorii, cât şi al STP, care, în timp, duc la tulburări somatice axiale şi de statică a pacientului, cu consecinţe simptomatice, clinice şi funcţionale. Răsunetul asupra sănătăţii pacientului este la nivel bio-psiho-social $(9,10)$.

Răsunetul cercetării este cu aplicabilitate largă: în sfera economică şi a sănătăţii publice, în ceea ce priveşte deschiderea unor direcţii de cercetare în domeniul ameliorării indicatorilor de incapacitate temporară de muncă, a rulajului pe pat de spital şi a produsului intern brut (PIB), rezultate prin profilaxia secundară şi terţiară a acestor anomalii bucomaxilo-dentare (11). 


\section{SCOPUL CERCETĂRII}

Scopul studiului este de a aborda integrativ patologia buco-maxilo-dentară de etiologie variată, astfel încât, plecând de la anomalia dentară, să prevenim dezechilibrele somatice, prin reechilibrarea sistemului tonic postural (STP). Cercetarea de faţă arată că acest deziderat nu poate fi realizat decât într-o echipă terapeutică pluridisciplinară, compusă din medicul dentist, medicul specialist în recuperarare medicală şi neuromusculară, medicul neuro$\log$, medicul ortoped şi medicul din asistenţa medicală primară. Tratamentul etiologic este, practic, cel care previne modificările somatice de la nivelul coloanei vertebrale şi nu terapia simptomatică. Tratamentul etiologic per se este o metodă de profilaxie secundară şi terţiară a tulburărilor somatice axiale (12).

\section{LOTUL DE STUDIU}

Lotul de studiu cuprinde un număr de 80 de cazuri clinice cu probleme de malfuncţie a aparatului buco-maxilar. Proporţia genurilor în lotul de studiu este de $43,75 \%$ bărbaţi şi $56,25 \%$ femei. Vârsta pacienţilor din lotul de studiu a fost cuprinsă între 6 şi 32 ani, ceea ce confirmă teoria apariţiei disfuncţiilor posturale la pacienţii tineri, care suferă de malocluzii.

TABELUL 1. Distribuția pe genuri a lotului de studiu

\begin{tabular}{|c|c|c|}
\hline Nr. cazuri & masculin & feminin \\
\hline 80 & 35 & 45 \\
\hline
\end{tabular}

\section{MATERIAL ŞI METODĂ}

În cercetarea de faţă, am utilizat următoarele metode de cercetare: analiza critică a relaţiei dintre ocluzia dentară şi postură, analiza literaturii de specialitate, observaţia, scoliometrii, podometrii şi studiul clinic pe un număr de 80 de cazuri, din practica de specialitate a cabinetelor medicale ale autorilor.

\section{REZULTATE ŞI DISCUȚII}

În urma analizei asocierii dintre malocluzie, poziţia capului şi influenţa corpului, a lotului de studiu, compus din cazuistica praxisurilor medicale ale autorilor, sunt prezentate principalele relaţii de cauzalitate, prin rezultatele cercetării.
În toate cazurile clinice luate în studiu, malocluziile au fost considerate ca rezultat al dentiţiei deficitare (anomalii dentare), fiind eliminate din etiologia malocluzală alte anomalii de tonus muscular sau alte afecţiuni la nivelul aparatului stomatognatic.

În lotul de studiu au fost diagnosticate anomalii ocluzale din clasa Angle, overjet, overbite, ocluzie încrucişată şi deviere a liniei mediene.

Din punct de vedere postural, s-au măsurat cu ajutorul scoliozometrului şi al podometrului următorii indicatori:

- poziţia posturală statică a corpului;

- poziţia posturală statică a extremităţi cefalice în timpul intercuspidării maxime;

- poziţia posturală statică a extremităţii cefalice în timpul deschiderii gurii, a mişcărilor de lateralitate, în timpul zâmbetului spontan şi al zâmbetului forţat.

Măsurătorile şi testările funcţionale au fost realizate atât înainte, cât şi după tratamentul ortodontic, pentru a stabili dacă au survenit modificări ale parametrilor posturali, secundar modificărilor indicatorilor (parametrilor) dentari.

TABELUL 2. Distribuția pacienților în lotul de studiu, în funcție de clasa Angle

\begin{tabular}{|c|c|}
\hline Clasa Angle & Nr. pacienți \\
\hline Angle 1 & 13 \\
\hline Angle 2 & 42 \\
\hline Angle 3 & 25 \\
\hline
\end{tabular}

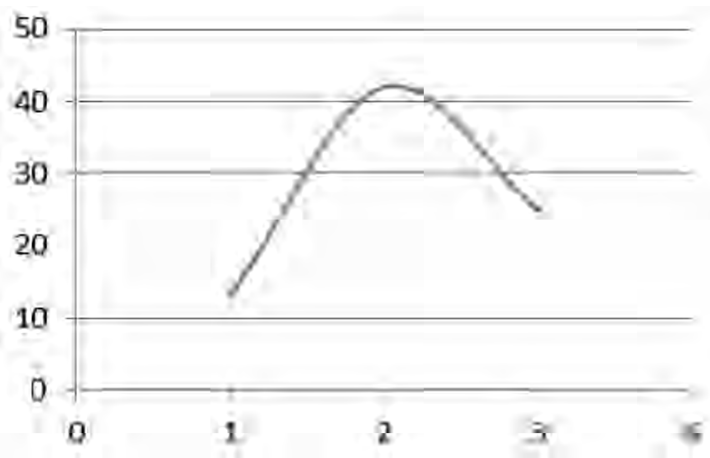

FIGURA 1. Distribuția pacienților pe clase Angle

Aşa cum reiese din tabelul 2 şi figura 1, cea mai frecventă anomalie ocluzală din clasa Angle este de tip 2, cu protruzia dentară superioară.

După realizarea unei corelaţii între anomaliile posturale şi anomalia de clasă dentară Angle la pacienţii din lotul de studiu, se constată că anomalia posturală respectă anomalia dentară, adică avem o 
corelaţie pozitivă pe cazuri clinice, accentuată pe clasa Angle 2, raportat la numărul de cazuri clinice (tabelul 3 şi figura 2).

TABELUL 3. Distribuția tulburărilor de postură la pacienții din lotul de studiu, în funcție de respectarea clasei Angle

\begin{tabular}{|c|c|c|}
\hline Clasa Angle & Nerespectat Angle & Respectă Angle \\
\hline Angle 1 & 3 & 10 \\
\hline Angle 2 & 14 & 28 \\
\hline Angle 3 & 16 & 9 \\
\hline
\end{tabular}

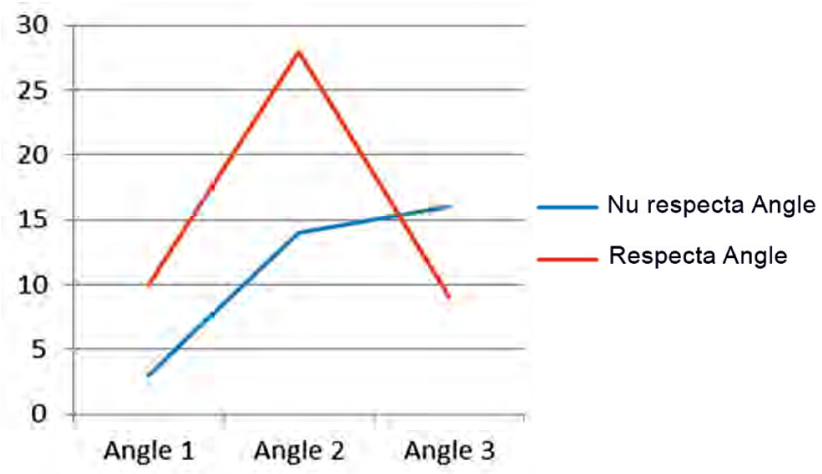

FIGURA 2. Corelația anomalii posturale şi anomalia de clasă dentară Angle

Examenul clinic arată că pacienţii de clasă 2 Angle prezintă des anomalii la nivelul grupului frontal. Aceasta determină o proiecţie anterioră a corpului şi a capului, fiind de multe ori factorul cauzal al tulburării posturale.

În urma corelaţiei statistice a etiologiei anomaliei dentare tip clasa Angle 2 la disfuncţionalitatea posturală, s-a realizat monitorizarea acestor pacienţi şi după tratamentul orodontic. Indicatorii posturali au fost măsuraţi şi comparaţi cu cei anteriori, după corectarea ortodontică. Rezultatele arată că se obţine un răspuns slab al ameliorării posturii pacientului doar în urma corecţiei ortodontice: 10,71\% (figura 3). Aceste rezultate arată necesitatea unui plan terapeutic complex, în echipa multidisciplinară de recuperare medicală neuro-musculară a anomaliilor aparatului buco-maxilar, corecţia dentară fiind doar o etapă a terapiei.

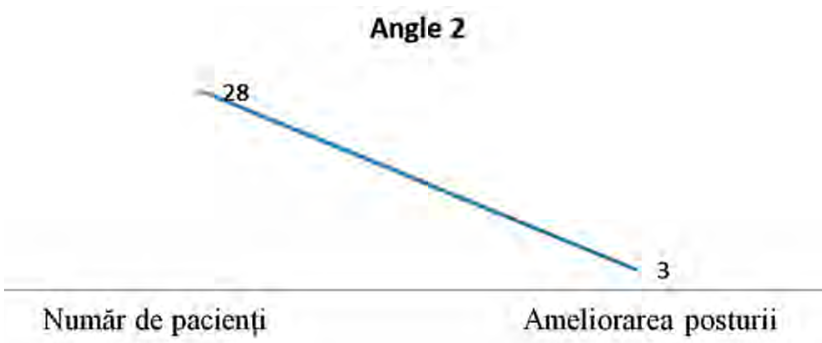

FIGURA 3. Ameliorarea posturii pacientului în urma corecției ortodontice
Metoda terapeutică de abordare a cazurilor clinice de anomalii dentare clasa Angle 2, prin tratamente etiologice, realizează reechilibrarea sistemul tonic postural (STP) plecând de la receptori dezechilibraţi, şi arată necesitatea unei colaborări strânse între diferite specialităţi medicale. Este de luat in considerare aportul oferit de tratamentele medicinei complementare, cum ar fi efectul inhibitor al acupuncturii asupra descărcărilor de reflex viscerosomatic (13). $\mathrm{Cu}$ alte cuvinte, ne permite tratarea cauzei principale a problemelor pe care le prezintă pacienţii şi nu numai a simptomelor. Echipa pluridisciplinară (medici şi cadre medicale medii din diverse specialităţi, psihologi şi asistenţi sociali) are un rol important şi în monitorizarea ulterioară a pacienţilor pediatrici şi tineri, de-a lungul etapelor de dezvoltare, posturologia fiind o ştiinţă care cuprinde mai multe discipline, cum sunt medicina dentară, neurologia, ortopedia, recuperarea neuromusculară $(10,14,15,16)$.

\section{CONCLUZII}

Studiul întreprins evidenţiază, prin rezultatele cercetării, necesitatea abordării cazurilor clinice a patologiilor dentare prin prisma bio-psiho-socială a sănătăţii individului, în conformitate cu accepţiunea OMS, în care tratamentul etiologic este cel care are rolul de prevenţie secundară şi terţiară. Abordarea integrativă în sfera medicinei dentare necesită implicarea terapeutică a unei echipe multidisciplinare.

Răsunetul cercetării este cu aplicabilitate largă: în sfera economică şi a sănătăţii publice, în ceea ce priveşte deschiderea unor direcţii de cercetare în domeniul ameliorării indicatorilor de incapacitate temporară de muncă, a rulajului pe pat de spital şi a produsului intern brut (PIB), rezultate prin profilaxia secundară şi terţiară a acestor anomalii bucomaxilo-dentare.

\section{Menţiune}

Toti autorii au contribuţie egală. 


\section{BIBLIOGRAFIE}

1. Roussouly P, Nnadi C. Sagittal plane deformity: An overview of interpretation and management. Eur Spine J. 2010 Nov; 19(11): 1824-1836.

2. Boboc G. Aparatul dento-maxilar, Ed. Medicală, 2009, 418-436.

3. World Health Organization. 2012. www.who.eu

4. Barbier L. Posture et statique chez l'enfant. Etude statistique realisee en milieu scolaire; Paris Archives du Collège International d'Étude de la Statique (C.I.E.S.), Marseille, 1994.

5. Azemar G. Les asymetries fonctionelles: Sport et lateralite. Travaux et recherches en EPS, Paris, INSEP, 1970, 4, p. 81-95.

6. Bergamini G. 2008. Dental occlusion and body posture: a surface EMG study; Cranio. 2008 Jan;26(1):25-32.

7. Bricot, B. 1998. La riprogrammazione posturale globale. Edit. Statipro, Marseille.

8. Ionescu E, Milicescu ID, Popescu M, Popoviciu O, Milicescu V. Ortodonţie şi ortopedie dento-facială, 2001, 85-88-89.

9. HJ Du, YF Chao. Localization of central structures involved in descending inhibitory effect of acupuncture on viscero-somatic reflex discharges. Scientia sin.19, 137 (1976).

10. Gavrilla LA. Psychological Particular Aspects in the Child-Dentist Medical Relation in the Dental Treatment, 15th World LUMEN
Congress - Logos Universality Mentality Education Novelty (LUMEN), vol. 15:371-376, Editura Lumen, laşi, 2016.

11. Gavrilă-Ardelean M. Politici sociale, asigurări de sănătate şi contribuții la managementul serviciilor de sănătate, vol. 1, ed. a II-a, în Colecţia „Politici sociale”, coord. Mihaela Gavrilă-Ardelean, Editura EIKON, 2019.

12. Gavrilă-Ardelean L, Gavrilă-Ardelean, Grivu ON. Stomatologie comunitară, în Colecţia Medica, Editura Mirton, Timişoara, 2009.

13. Shimazaki T, Motoyoshi M, Hosoi K, Namura S. The effect of ocllusal alteration and masticatory imbalance on the cervical spine, The European Journal of Orthodontics 2003. 25(5):457-63.

14. Gavrilă-Ardelean M. Serviciile sociale specializate şi activitatea asistentului social în cazul pacienţilor cu boli cronice, Revista AS\&PS Agora Psycho-Pragmatica Nr.6, Editura Universităţii „Aurel Vlaicu” Arad, 2008, ISSN: 1842-6840, pg. 41-45.

15. Gavrilă-Ardelean, M., Gavrilă-Ardelean, L. Elemente de medicină internă şi socială: note de curs, Ed. a 2-a, rev. şi adăug., Colecţia Medica, Editura Şcoala Ardeleană, Cluj-Napoca, Editura EIKON Bucureşti, 2016.

16. Cuccia, A., Caradonna, C. 2009. The relationship between the stomatognathic system and body posture. Clinics, 64:61. 